\title{
Ian Brack: 'We are going to get better at what we do'
}

Interview by Kate Quinlan

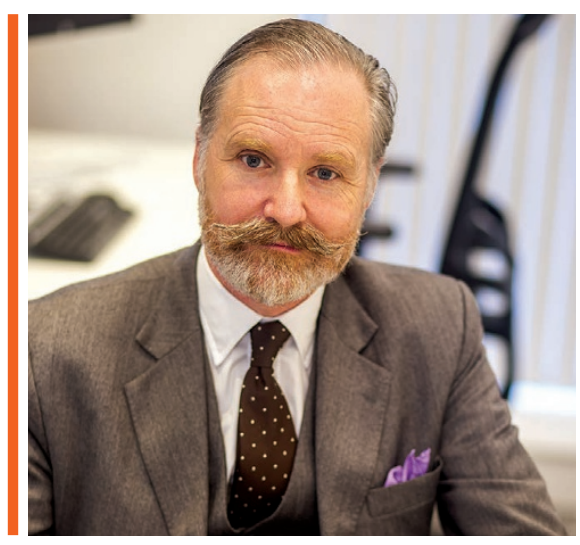

How are you finding your role

Fascinating. Interesting. Quite challenging.

It's an organisation going through signifi-

cant change so the challenge is to keep the service to the level it needs to be, and to make the changes that need to be made and direct that change in positive ways. It's genuinely enjoyable. It's a new sector for me and not an area I've worked in before. Legal regulation I know but health regulation is something new.

\section{How does being Chief Executive of the GDC compare to your past roles?}

All sectors have their own language; health regulation has a kind of health regulation language, a 'health regulation way' of looking at the world. It is different to legal regulation which is perhaps more about being willing or able to, because of the nature of the job, consider mediations as an approach because you're very often not dealing with direct physical harm, or life threatening things, so there is a difference there. But overall it is curious how much the handling of grants, which is what I've done for much of my life, and the handling of one form of complaints or another are basically very similar things: they're about dealing with casework and getting casework to an appropriate conclusion.

Ian Brack was appointed Chief Executive of the General Dental Council (GDC) in May this year, after a period as Interim Chief Executive starting in January. Prior to joining the regulator, he was Chief Executive at the Office for Legal Complaints. He also led the Olympic Lottery Distributor where he oversaw substantial grant expenditure, including the multi million pound grant for the Paralympics.

It is about processing and doing it fairly, transparently, and as quickly and effectively as you can.

\section{Have you enjoyed attending events and Conference this year and meeting dental professionals?}

That's fantastic and much more fun than most other things I get to do. Anything that gets you to meet people who are actually doing things - the people you are regulating and the public - are all good. It is interesting because you get entirly new perspectives. Like I say, regulators are a culture in themselves; the people you regulate are another culture. You get an interchange which is really good. I don't get to do enough of that but there is of course a business to run. I can't go swanning off all the time, as much as I would like to.

\section{Have you felt welcomed by the people you have met?}

Yes, I really have. It's a funny thing; I'm used to being someone with great wodges of money in my back pocket which makes you popular in a kind of venial way, as everyone wants something from you when you're a grant giver. [Being GDC CEO] is quite different as people are not after money, they just want to tell you things, they want to talk to you. It's very interesting and I like it.

\section{Do you feel that you are making good progress towards achieving the GDC's ambitions?}

We have very big ambitions so my progress in the short term is good enough. When you build things there is a long period of time when nothing seems to be happening. It's all going in the ground, that's where the money and the work is in the building, it's all below the ground. If you get that right then it all works. If you get in wrong then it doesn't matter how good the later stuff is, it doesn't stand. We're working hard and we're getting stuff done. I'm pleased with progress but there's loads more to do. I won't be bored.

\section{Questions from our readers}

Question from Alan Lawrence:

Your predecessor Evlynne Gilvarry was universally disliked for 'ousting Alison Lockyer'. It seemed to be Ms Gilvarry's measure of success to prosecute as many dentists as possible. The appalling hike of the ARF is viewed by the profession as legalised theft. What are you going to do to restore confidence in a GDC that is still led by a non-dentist and so is viewed with huge suspicion by a large part of the profession? Ian's response:

There are a few things in there that I wouldn't agree with. I don't think you'll be surprised to hear that. What are we going to do? We are 
going to get better at what we do. We are going to demonstrate that the money that is provided to the regulator to carry out its job is used as effectively and efficiently as possible. But we are going to go further than that. One of the big problems is that the model of regulation which we have to use, and I stress 'have to' because it is in the Act, is inherently inefficient in some ways. But there are significant things that we can do to make it more efficient without legislation and we are going to explore all of those. We also believe that what we can do is to work with the professions, with the sector as a whole and with the NHS and other regulatory bodies and other health bodies, to fundamentally change the way that we work in regulation. We've got fitness to practise [FTP] - and no, it isn't our measure of success to prosecute as many people as possible - the way I look at it is that every time I open the toolbox to do anything I've got a hammer in it with FTP written on the side. If I am going to hammer nails in then that's great. If I am going to mend a watch then it's not very useful. There are some problems, many problems, which we encounter from day to day be tremendously challenging to introduce any legislation because of all the other work that will need to be done. I don't think anyone pretends the system we have now, and I'm talking about the wider healthcare system, is by any means perfect. I would still hope to see change over time but the idea that we are given enough time to actually show the improvements we are trying to invest in. I think that's a good thing overall, certainly from my perspective. If we are to continue as we are then we have to make the best of what we are, that's how I see it. I relish the opportunity is perhaps the best way of saying it.

\section{Question from Callum Youngson:}

Are there any plans to change the GDC's 'strapline' from 'Protecting patients - regulating the dental team' to something more positive like 'Ensuring patient care - developing the profession, akin to the GMC's strapline, 'Working with doctors - working for patients'? This would more accurately reflect the wider regulatory and developmental role of the GDC, including its educational QA role.

\section{'The way I look at it is that every time I open the toolbox to do anything I've got a hammer in it with FTP written on the side. If I am going to hammer nails in then that's great. If I am going to mend a watch then it's not very useful.'}

which FTP really isn't the solution for and it is our job to make sure that they aren't dealt with by FTP. Our job, our task, our challenge, is to work with the profession and other regulators to get the problems dealt with in the way they best can be. If it comes to us, FTP is what we've got, what we have to do. But we are fully aware that it's not the right thing on every occasion. We want to work with the profession and challenge them to help us widen the options and help us get things upstream, finding local resolution for problems, and get better at dealing with problems early.

\section{Question (Name supplied):}

It was widely anticipated that the government was planning to merge many of the smaller regulators. Are you pleased that Brexit may well have given the GDC a stay of execution? Ian's response:

We don't know for sure that plans for legislation are definitely shelved. It's going to

\section{Ian's response:}

'Protecting patients - regulating the dental team' is as succinct a description of what we have to do as I can think of. In a way I found it very useful when I came here as a sort of indicator of the absolute basic purpose of the organisation. We don't have plans to change the strapline in the short to medium term. It's the label on the tin: it's what we do.

\section{Question from James Hardy:}

I have on many occasions enquired as to why the GDC does not have a Retired Membership Section like the GMC. I am told that if I was a retired member, my details would still need to appear on the Register and a patient might find my details and contact me for an appointment! A retired member would still be able to practise as an Expert Witness, perhaps continue to do voluntary work overseas etc, continue to be able to attend meetings and claim CPD. The extra but reduced subscription rate generated could potentially allow a reduction in the ARF. A dentist I spoke to in Manchester at the BDA Conference said that in order to have a retired section there would have to be a change in the legislation. If an enlightened leadership decides to introduce a retired section, would those of us who left several years previously be allowed to return to the fold without having to produce CPD certification for the years we had been off the Register? Ian's response:

We don't have plans to introduce a retired register. The register simply indicates that you can practise. If you're retired and you don't want to practise then you've come off it. What I think people sometimes fail to understand is, running a multiplicity of different registers, or different schemes, has an admin cost which will counterbalance any benefits from it.

Question from Norma Ross:

What is the GDC going to do about dentists who report other dentists to the GDC out of vindictiveness and abuse? Should there not be a system to check out the dentist who has made the complaint first - by checking locally with the health board or practice advisor? Especially since the complaint has not come from a patient. And should there not be repercussions for the dentist reporting if it can be shown to be abuse? Ian's response:

We have to investigate complaints that we receive. If there is no substance to a complaint our aim is to get it out of the system as early as possible, triaging it out as quickly as we can. If that investigation were to show that there was absolutely no substance to a complaint or there was some counter-complaint or that it was malicious, we'd have to investigate that as well. I think the balance comes in that regard. Justice can be served in that way. There is a presumption there of prescience which I'm afraid we don't have in my experience of the public sector. We may be assiduous but we have to look at things on the face of them and go through the investigatory process.

Question from Roger Levy:

Do you, like GDC Chair Bill Moyes, see dentistry as a supermarket 'Lidl to Waitrose' model? Going from that view, do you accept that Lidl and Waitrose offer very different product ranges? If you agree with Mr Moyes, how would you describe the NHS offer? 
Cheap, cheerful but definitely limited in range, or no different from a private offer other than in terms of comfort and time? If the latter, how is an NHS dentist (like me) to deal with a patient asking for a treatment that will cost more in time or money than the NHS provides, without risking GDC attention? Ian's response:

The Chair was trying to give a comparison which people understand. Everybody shops; it doesn't mean that running a dental practice and running a supermarket are exactly the same. They all have their complexities, risks and difficulties. The Lidl to Waitrose model is one way of looking at the world. The NHS is a state monopoly and sits alongside the market; it's a different animal altogether so making straight comparisons is pointless.

It just isn't the same. I think that question is really touching on the contract which dentists have with the NHS and that is outside of our locus. I can't comment on that as I have no basis on which to do so. There is a little subtext there which is do we think dentists are just like shopkeepers. No. There's an element of dentistry which is about patient care and provision of clinical services. Dentists also have to run a business. Some of them run an overtly private business. So there is a real range which I think is one of the curiosities about dentistry. It is quite different to many of the other health professions and understanding that range and dealing with that and understanding the different pressures that dentists have to deal with is part of what we have to do. We have to recognise that there is a business as well as a clinical practice. That there is a duty of care but also a need to make a payroll at the end of the month. We have to respect that.

\section{Question from Paul Jones:}

An article was recently published in the Times Higher Education, which set out concerning allegations relating to the qualification of students at UCL Eastman Dental Institute (EDI) (www.timeshighereducation. com/news/wrong-marks-for-dentistrystudents-spark-investigation). In short, hundreds of students on dental degrees at EDI were, over many years, given the wrong marks for their work. This led to students being given incorrect transcripts that did not reflect their actual performance and having their final awards wrongly classified. It is also reported that some students were incorrectly failed when they should have passed.
From the article, it seems that UCL and EDI have been less than forthcoming about the situation and are accused of 'dragging their feet'. This is a clear failure of UCL's internal governance but also of the risk-based approach to quality assurance taken by the QAA (the HE regulator).

What role can the GDC play in such circumstances and what consequences are there for such a provider given its role in National Training? stay the same. It is a problem when you get to excessive levels of detail in legislation, for example where fees are tied into legislation and named. There are many things we can do. We are looking very, very closely at what lies within our grasp to do without legislative change, what lies within the wider grasp of the sector to do by behavioural or process change which doesn't need legislative change. We are looking at our interpretations of legislation because actually the law doesn't

\section{'We know that we don't deal with a monolithic dental sector that is homogenous. We would be daft if we didn't know that.'}

\section{Ian's response:}

So this is a postgraduate dental school. This is an area of dental education that we don't regulate. If we are to move into that then it's something which we need to work with others to discuss whether it's the appropriate thing to do. It would have a resource implication and be an extension of our role. It would have a cost. I am always interested in how much everything costs because I'm the one who ultimately has to account for the money. It is not something at the moment that we police and we are conscious of that and conscious of these gaps. The question is what is the right answer for dealing with the gaps? It's something the professions and the GDC need to talk about to explore.

\section{Question from Paul Batchelor:}

One of the major barriers to helping bring about better regulation has been cited as the need for legislative change. Do you think this is a valid point and, if yes, how can the profession engage best in the political machinations to alter the existing legislation? What aspects of the care system in your view need changes in the legislation before they can be implemented?

Ian's response:

It is a valid point in as much as a public sector body is tightly bound by its powers. Within its powers it can do a tremendous amount but it can't exceed them and that is genuinely problematic. It can get very strange with older legislation which often was designed for professions that were very different. Legislators, like most people, can't predict the future, and in the past probably thought that many things would lay down exact detail; there is an interpretative element and interpretation changes over time. You need to go back to them and think, does that reflect common sense? We are doing that process of looking at it. We are really interested in the things that are about will to change and skill to change rather than about legal change. My ambition is that when we say we can't do this because the law stops us, you will know that we have explored that to the limit and we really can't. Over time there will always be the possibility to make relatively small secondary legislative change and when we can we will do that. When it comes to a primary legislative change what the profession needs to do is get a consensus view about what it wants and a considered one then use their professional bodies to lobby for that; that's the best way to do it.

If I can drive change forward with the advice of our experts and legal advisors and if the change will be beneficial then I will try and do it.

\section{Question from Jenny Gallagher:}

How does the GDC balance their governance across countries and the different dental professions?

Ian's response:

Multiple stakeholders have differing priorities and ambitions. A good regulator learns what those are and engages with them and strikes a balance between them. We are very aware that we deal not with one NHS but four. They're all subtly different, all with their own bureaucracies and priorities. We're working with those and learning those and we have people whose job it is to understand them. We also have our eye 
on the future because like any public sector body we need to be aware of potential future change and factor that in to our planning. There may be very significant changes over time to the relationship between the various devolved administrations and Westminster, a continuum which could go in some cases from independence to greater fiscal powers. We don't know and we watch it constantly and keep on top of it. We have council members who are linked to the different parts of the UK and have staff who watch them and engage with the NHS, government and local bodies and the different professions. We know that we don't deal with a monolithic dental sector that is homogenous. We would be daft if we didn't know that. We can't always provide a bespoke solution to each different sector and country because we are not rich, but we factor it in.

A second question from Jenny Gallagher: The GDC communications team provide advice to patients on questions to ask their dentist (this no longer seems to be online) but all the advice is largely traditionally treatment focused. Why is there no emphasis on prevention of disease? Ian's response:

Interestingly one of the things we are starting to talk to dentists about is about how we get people to understand what good is. When you're dealing with patients it's about saying what is good for you. This is a thing for the profession to do - and they're the experts - say you're going to have a better time with us if you take these preventative steps. What we need to do is support the profession in doing that. We're not the clinical experts. I think it's our job to say, okay profession, how are you dealing with that, if we can help then we will help. Our job as regulator pulls us towards saying to the patients: these are the questions you need to ask about your experience at the dentist. In the end it's the clinicians who have the expertise and the authority to give advice.

\section{Question from Jonathan Lewney:}

A lot of the tension between the GDC and the dental profession could be seen as being due to legislation that the GDC has no control over. If this were not the case, and you had total autonomy in your role, what one thing would you do to help restore the faith of the dental profession in their regulator?

Ian's response:

Firstly, I think that we can't hide behind legislation and we don't want to hide behind legislation. We can take many steps to improve that ourselves: being more transparent, being better at what we do, being more effective, but also being more efficient. So we demonstrate that for what we cost we are providing value for money, we are doing the job and we are doing it well and doing it as quickly as possible. There is no panacea. There is no one thing I could say: if I could do that, bang, problem solved, but what I would like to be able to do is systemically try to remove any obstacles to the expedient handling of cases. Where we know that cases are not going to go right to the end of the process - there are occasions where legislation prevents us removing those cases as quickly as we would like to - it would be very good if we could shave those off. We are looking very closely at what else we could do on that score anyway. We are looking at every opportunity to streamline without for one moment sacrificing the quality of an investigation.

\section{Is there anything else you would like to communicate to $B D J$ readers?}

I think that the message I would really like to pass on is this. One thing I've noticed about the way people feel about the GDC is that the system that the GDC has to deliver is flawed. We know that and we are trying to do something about it. The process and the organisation aren't the same creature. Frustration at the process is understandable but try to remember, we aren't the process. The second thing is to say, we've been through a hard few years with a lot of learning and the organisation has learnt. When I arrived here I came to an organisation which had had a bruising time but had clearly learnt lessons from it and was trying really hard to do something about it. That's the one I came to but not the organisation that I am leading now. We've been able to step up a gear since then as we have more new people in place who do different jobs that we realise need to be done. We are changing. We are not the organisation we were a year ago, let alone two years ago. Sometimes when people talk to me about how dreadful the GDC is the examples they cite might be five years old. The past is another country and we aren't the same. Judge us on what we do and not what was done in the past. And we will make it our business to be worthy of the judgement.

We are really focused on achieving higher standards of service. PSA standards are not the be-all and end-all but we are driving our performance against those very hard, so that we can demonstrate to the wider world that we have made changes. We have got better. Once you have lost standards regaining them is hard but we are working really hard to embed those in everything we do. Alongside that we are doing all the things I have talked about, trying to change and improve, and the profession should see evidence of that improvement in the coming year. It is very important that we drive our change through those things and when we think the standards are not enough we will do more. 